\title{
Discovery of the Common House Gecko, Hemidactylus frenatus (Duméril \& Bibron), in Puerto Rico
}

\author{
Alejandro Sánchez
}

36 Calle Nevarez, Apt. 3-G, San Juan, PR 00927-4523, USA (ajtgsm@gmail.com)

Date of publication: 4 September 2018.

Citation: Sánchez A (2018) Discovery of the Common House Gecko, Hemidactylus frenatus (Duméril \& Bibron), in Puerto Rico. Caribbean Herpetology, 60, 1-2.

DOI: $10.31611 /$ ch.60

I report the first record of the Common House Gecko, Hemidactylus frenatus, from Puerto Rico. On 24 January 2017 I collected a male individual (Fig. 1) on the floor of a military barracks in Camp Santiago Joint Maneuver Training Center in southeastern Puerto Rico $(18.0075,-66.2956)$. I collected a female and a juvenile in the same area on 16 March 2017 and 9 July 2017, respectively. I photographed them all and preserved them in $70 \%$ ethanol. The female and juvenile, plus an additional male, are deposited in the Museum of Zoology of the University of Puerto Rico, Rio Piedras

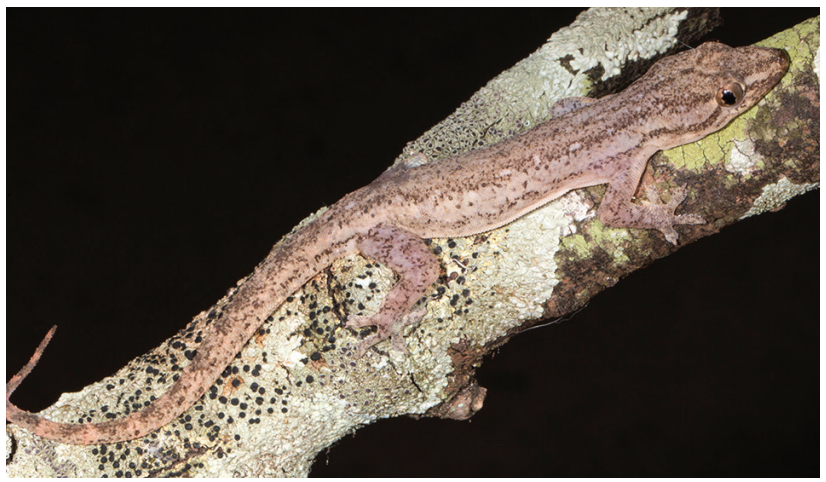

Figure 1. A male Hemidactylus frenatus at Camp Santiago, Puerto Rico. Campus (UPRRP 1505-1507).

Two other species of Hemidactylus have been reported from Puerto Rico (Rivero, 1998): the West African House Gecko, H. haitianus Meerwarth (Fig. 2), and the Tropical House Gecko, H. mabouia Moreau de Jonnès (Fig. 3). In Camp Santiago, H. mabouia was commonly seen in these buildings until at least mid-2015, but it is now seldom seen there (personal observation). One possible cause of this change may be the arrival of $H$. frenatus, which occupies the same areas as H. mabouia, suggesting that $H$. frenatus outcompetes H. mabouia in and around buildings. Now, H. mabouia is commonly seen only in xeric pasture and woodland located less than a kilometer from the buildings.

The three species are similar in size and appearance and are easily confused but have differences in scalation and body proportions. For example, the head and snout of $H$. frenatus is narrower than in the other two species. In pattern, H. haitianus possesses a dorsal series of dark, hourglass-shaped blotches whereas H. mabouia has a dorsal series of dark, V-shaped markings pointing toward the tail. Hemidactylus frenatus is weakly patterned with a light lateral stripe bordered above and below by two darker stripes. A thin middorsal stripe, lighter or darker than the ground color, might also be present in $H$. frenatus. All stripes begin near the tip of the snout and continue onto the tail. These color differences may be unreliable at night, when adult individuals of all three species usually turn pale (personal observation).

Like several other Hemidactylus species, H. frenatus is accidentally distributed to new regions through human-mediated means (agricultural produce, luggage, etc.). The species has been recorded from South America and the Galápagos Archipelago only recently (Torres-Carvajal, 2015). Later in 2015, it had spread to several countries in North, Central, and South America (Global Invasive Species Database, 2015). Although Camp Santiago is not located near any main trade or travel destination, this military installation hosts personnel arriving from several countries on both American continents. It is reasonable to assume that $H$. frenatus arrived as a stowaway in luggage or equipment coming from those regions. 


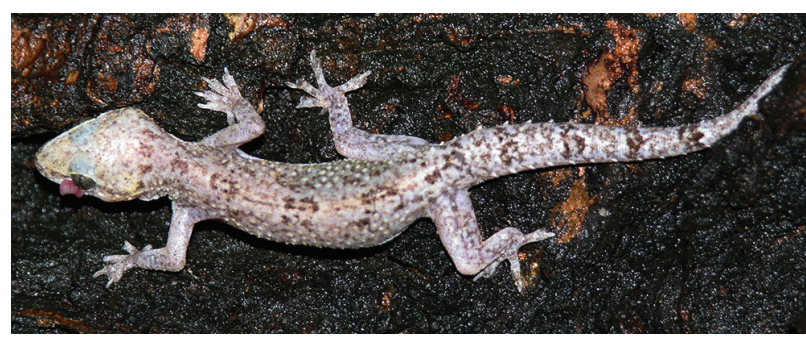

Figure 2. Hemidactylus haitianus from Trujillo Alto, Puerto Rico.

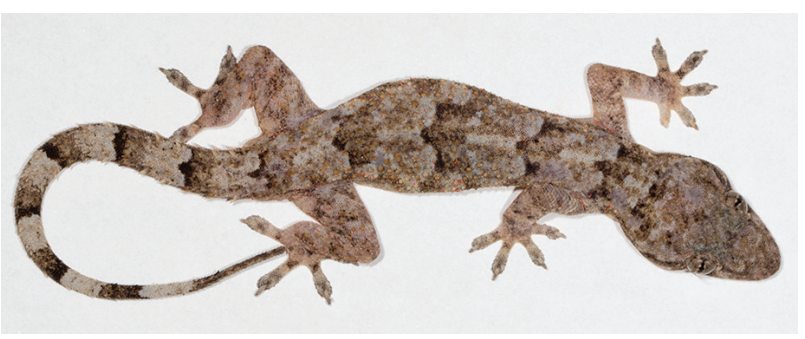

Figure 3. Hemidactylus mabouia from Camp Santiago, Puerto Rico.

\section{Acknowledgements}

I thank Aaron M. Bauer (Villanova University) for his assistance in identifying the species.

\section{References}

Global Invasive Species Database (2015) Hemidactylus frenatus. Available online at http://www.iucngisd.org (International Union for Conservation of Nature, Gland, Switzerland). Accessed 1 July 2018.

Rivero, JA (1998) The Amphibians and Reptiles of Puerto Rico, Second Edition (Editorial de la Universidad de Puerto Rico, Rio Piedras, Puerto Rico).

Torres-Carvajal, O (2015) On the origin of South American populations of the Common House Gecko (Gekkonidae: Hemidactylus frenatus). NeoBiota, 27, 69-79. 